\title{
Hospitalizations for cardiovascular diseases and the coverage by the family health strategy ${ }^{1}$
}

\author{
Maicon Henrique Lentsck² \\ Thais Aidar de Freitas Mathias ${ }^{3}$
}

Objective: to verify the correlation between the rates of hospitalization for primary care-sensitive cardiovascular diseases and the coverage by the Family Health Strategy of residents of the State of Paraná, by regional health divisions, from 2000 to 2011. Method: ecological study developed from data of the Hospital Information System of the Brazilian Unified Health System (SUS) and the Department of Primary Care of the Ministry of Health. The rates of hospitalization for cardiovascular diseases were correlated with the annual coverage by the Family Health Strategy using Pearson's and Spearman's correlation coefficients. Result: there was a strong and negative correlation in the State of Paraná $(r=-0.91 ; p<0.001)$ and in most regional health divisions, with the highest correlations observed in the Metropolitan and Toledo $(r=-0.93 ; p<0.001)$ and Paranaguá $(r=-0.92, p<0.001)$ regional health divisions. Conclusion: the results suggest that the increase in the coverage by the Family Health Strategy was an important factor for decrease in the hospitalizations for cardiovascular conditions among residents of the State of Paraná and in most regional health divisions. Other studies should be performed to analyze the factors and causes in regional health divisions where there was no correlation with increase in the Family Health Strategy.

Descriptors: Cardiovascular Diseases; Hospitalization; Primary Health Care; Family Health Strategy; Public Health Nursing.

\footnotetext{
${ }^{1}$ Paper extracted from master's thesis "Admissions due to cardiovascular conditions sensitive to primary health care in the state of Paraná Brazil", presented to Universidade Estadual de Maringá, Maringá, PR, Brazil.

2 Doctoral student, Universidade Estadual de Maringá, Maringá, PR, Brazil.

${ }^{3}$ PhD, Full Professor, Departamento de Enfermagem, Universidade Estadual de Maringá, Maringá, PR, Brazil.
}

Corresponding Author:

Maicon Henrique Lentsck

Rua Conde D'eu, 531

Vila Carli

CEP: 85040-290, Guarapuava, PR, Brasil

E-mail: maiconlentsck@yahoo.com.br
Copyright (๑) 2015 Revista Latino-Americana de Enfermagem This is an Open Access article distributed under the terms of the Creative Commons Attribution Non-Commercial License (CC BY-NC).

This license lets others distribute, remix, tweak, and build upon your work non-commercially, and although their new works must also acknowledge you and be non-commercial, they don't have to license their derivative works on the same terms. 


\section{Introduction}

The access and quality of care provided by the Primary Health Care (PHC) are key elements of the health systems to address the challenge of the increasing prevalence of Cardiovascular Diseases (CVD) in the population. In 2008, these diseases accounted for twothirds of the 36 million deaths worldwide ${ }^{(1)}$. Individuals with CVD are more likely to hospitalization, considering the high risk of functional impairment, adverse events related to the action of medications and patient's reactions, as well as the occurrence of comorbidities ${ }^{(2)}$. The impact of hospitalization on the quality of life of individuals and their families can be high and represent high costs. In Brazil, in 2012 there were 1,137,024 hospitalizations for CVD by the Brazilian Unified Public Health System (SUS), with a total cost of $R \$ 2,381,639,909.14^{(3)}$.

The effectiveness of the actions performed by the $\mathrm{PHC}$ has been investigated by means of hospital activity indicators, based on the assumption that high rates of hospitalization for primary care-sensitive conditions may result from lack of access to primary health care

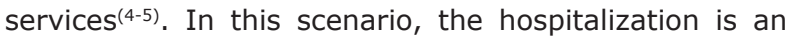
element that signals problems in the health sector(5), capable to translate the real situation of the population ${ }^{(6)}$ and provide input to the development and monitoring of PHC.

In Brazil, the PHC has a long history in the public health care system, important for achieving the principles of SUS and institutionalization of the main current public health policy - the Family Health Strategy $(\mathrm{FHS})^{(7)}$ which, in addition to improving the access and quality of primary care, aims at reorganizing the care practice ${ }^{(8)}$. Consequently, at SUS, the PHC is the gateway to the individual and collective health needs, organized based on a full care cycle: duration of the health condition, coping strategy and health care system structure(9).

The Primary Care-Sensitive Conditions (PCSC) are health problems that can be treated timely and effectively at PHC, without the need for hospitalization(5). The PHC characteristics associated with the risk of hospitalization for PCSC, were reviewed and showed increasing consistency of negative correlation between access to ambulatory services and hospitalization for PCSC. It was also identified that the continuity of work, multidisciplinary teams and the registered population size were associated with a lower probability of hospitalizations(5).

Some CVD, such as Systemic Arterial Hypertension $(\mathrm{SAH})$, angina, Congestive Heart Failure (CHF) and cerebrovascular diseases are examples of health problems contained in the Brazilian List of Primary CareSensitive Conditions, which can be used as markers in the evaluation of the basic health services because they are considered potentially avoidable ${ }^{(10)}$.

Acute myocardial infarction, stroke, and heart failure are complications that can be prevented by FHS actions, developed at PHC. Among these actions, it is highlighted early detection, high-risk diseases treatment and mainly cardiovascular evaluation, medical monitoring and medical advising(1). The CVD present a model of intervention at $\mathrm{PHC}$ that responds positively to the actions implemented appropriately and efficiently, limiting the hospitalization process and providing information about the different health conditions, and subsidizing intervention processes. The evaluation of Primary Care-Sensitive Cardiovascular Conditions (PCSCC) can also be used to monitor inequalities in the distribution of access to quality primary care, contributing to the debate on interventions that include a fair funding system, basic technologies, essential medications, trained health staff, medical information as well as referencing systems and networks ${ }^{(11)}$.

In Brazil, studies correlating the hospitalizations for PCSC and the coverage by the FHS showed negative correlations $^{(12-13)}$, with inverse relation of values among indicators. This correlation was not found between mortality rates for CVD and the coverage by the FHS in Brazil or in its states ${ }^{(14)}$. To date there are no studies showing this correlation for the State of Paraná and for the regional health divisions. Hence, in the present study it was verified correlation between the rates of hospitalization for primary care-sensitive cardiovascular conditions and the coverage by the FHS of residents in the State of Paraná, by regional health divisions, from 2000 to 2011.

\section{Method}

Exploratory ecological study focused on hospitalizations for primary care-sensitive cardiovascular conditions and on the population coverage by the FHS, estimated for the State of Paraná, according to regional health divisions, from 2000 to 2011.

The diagnoses of the cardiovascular conditions group were classified according to the Brazilian List of Primary Care-Sensitive Conditions ${ }^{(10)}$, which encodes the sensitive conditions according to the tenth revision of the International Classification of Diseases (ICD-10): SAH (ICD-10 : I10 and I11), angina (ICD-10: I20), CHF (ICD-10: I50 and J81) and cerebrovascular diseases (ICD-10: I63 to I7, I69, G45 and G46). 
The hospital data were obtained from the Hospital Information System of SUS (SIH-SUS), monthly available on the website of the Computer Department of SUS (DATASUS). The SIH-SUS is based on the data from the Hospital Admission Orders (HAO), which are documents completed by the physician in each hospitalization financed by the public sector, aiming at identifying the patient, the hospitalization diagnoses, the hospital expenses, and used to that the hospital receives reimbursement for the services provided. For this study, it was adopted HAO type 1 , considering all hospitalization of residents in the 399 municipalities of the State of Paraná, grouping them, later, in 22 regional health divisions. The population data of residents in the state and in the regional health divisions, used to calculate the hospitalization rates, are also available at DATASUS, whose reference is the Brazilian Institute of Geography and Statistics (IBGE).

The hospitalization rates were calculated considering the total number of hospitalizations caused by primary care-sensitive cardiovascular conditions of residents of the state and regional health divisions, aged between 35-74 years, divided by the population of the same age, place and period and multiplied by 10,000 . It was considered the population aged between 35-74 years, as the age of 35 increases the possibility of illness and hospitalization for CVD, and 74 years is considered the age limit for public policies focused on promotion and prevention of morbidity and mortality caused by CVD(15).

The calculation of the coverage by the FHS was performed by means of the ratio between the population covered by the FHS in the last month of each year in the state and in the regional health divisions, per inhabitant, multiplied by 100 . The population estimates of the comprehensiveness of the FHS services, in the defined territory, were consulted in the website of the Department of Primary Care of the Ministry of Health, which provides monthly information on the cities and states.

The correlation analysis was performed between the rates of hospitalization for PCSCC and the proportion of coverage by the FHS in the state and in the regional health divisions, from 2000 to 2011, using the Pearson's correlation coefficient and the Spearman's correlation coefficient when data were not normally distributed, with a significance level of $5 \%$ ( $p$ $<0.05$ ). For interpreting the magnitude of correlation coefficients it was adopted the classification proposed by Hulley et $\mathrm{al}^{(16)}$ : correlation coefficients $<0.4=$ weak magnitude correlation, $\geq 0.4$ to $<0.5=$ moderate magnitude correlation, and $>=0.5$ strong magnitude correlation. In order to facilitate the comparison over the time researched, the hospitalization rates were grouped in triennia and the relative difference was calculated between the extreme triennia. The database tabulation, the hospitalization rates calculations and the population coverage by the FHS were performed using Microsoft Office Excel software (version 2007), and for the correlation analysis it was used the SPSS software (version 18.0). The study was appreciated by the Ethics Committee and dispensed of analysis (Opinion number 037/2012-Copep), considering the nature of research and a unique methodological design, with secondary data and public access via the Internet.

\section{Results}

In the period considered in this study it was found an increase in population coverage by the FHS of $81.9 \%$ and decline of $35.3 \%$ in the rates of hospitalization for PCSCC in the state of Paraná. For the coverage by the FHS, it was observed a relative increase in all regional health divisions, especially in the regional health division of Paranaguá (454.8\%), Foz do Iguaçu (277.1\%) and Telêmaco Borba (212.4\%), which had the largest positive variations, while Londrina (19.7\%), Apucarana $(18.7 \%)$ and Cascavel $(10.6 \%)$ had the smallest positive variations (Table 1 ). It was observed a decline in the rates of hospitalization for CVD and a difference between the regional health divisions, with the most pronounced relative decrease in Maringa $(-49.9 \%)$, Paranaguá $(-48.3 \%)$ and Umuarama $(-45.3 \%)$ and less pronounced relative decrease in the regional health division of Cornélio Procópio (-4.3\%) and Telêmaco Borba $(-4.1 \%)$. The exception was the relative increase of $3.8 \%$ in the rates of hospitalization for PCSCC for residents in the regional health division of Ponta Grossa (Table 1).

In Figure 1, it was distributed spatially, the magnitude of the correlation coefficients in the State of Paraná, by its regional health divisions. The correlation between the rates of hospitalization for PCSCC and the coverage by the FHS was strong and negative for the State of Paraná $(r=-0.91 ; p<0.001)$, and higher for the regional health divisions Metropolitan and Toledo $(r=$ -0.93; $p<0.001)$ and Paranaguá ( $r=-0.92, p<0.001)$. There was no significant correlation in the regional health divisions of Ponta Grossa, Cascavel, Londrina, Cornélio Procópio, Telêmaco Borba and Ivaiporã, showing stability or slight decrease in the hospitalization rates, or moderate increase in the coverage by the FHS (Table 1 and Figure 1). 
Rev. Latino-Am. Enfermagem 2015 July-Aug.;23(4):611-9.

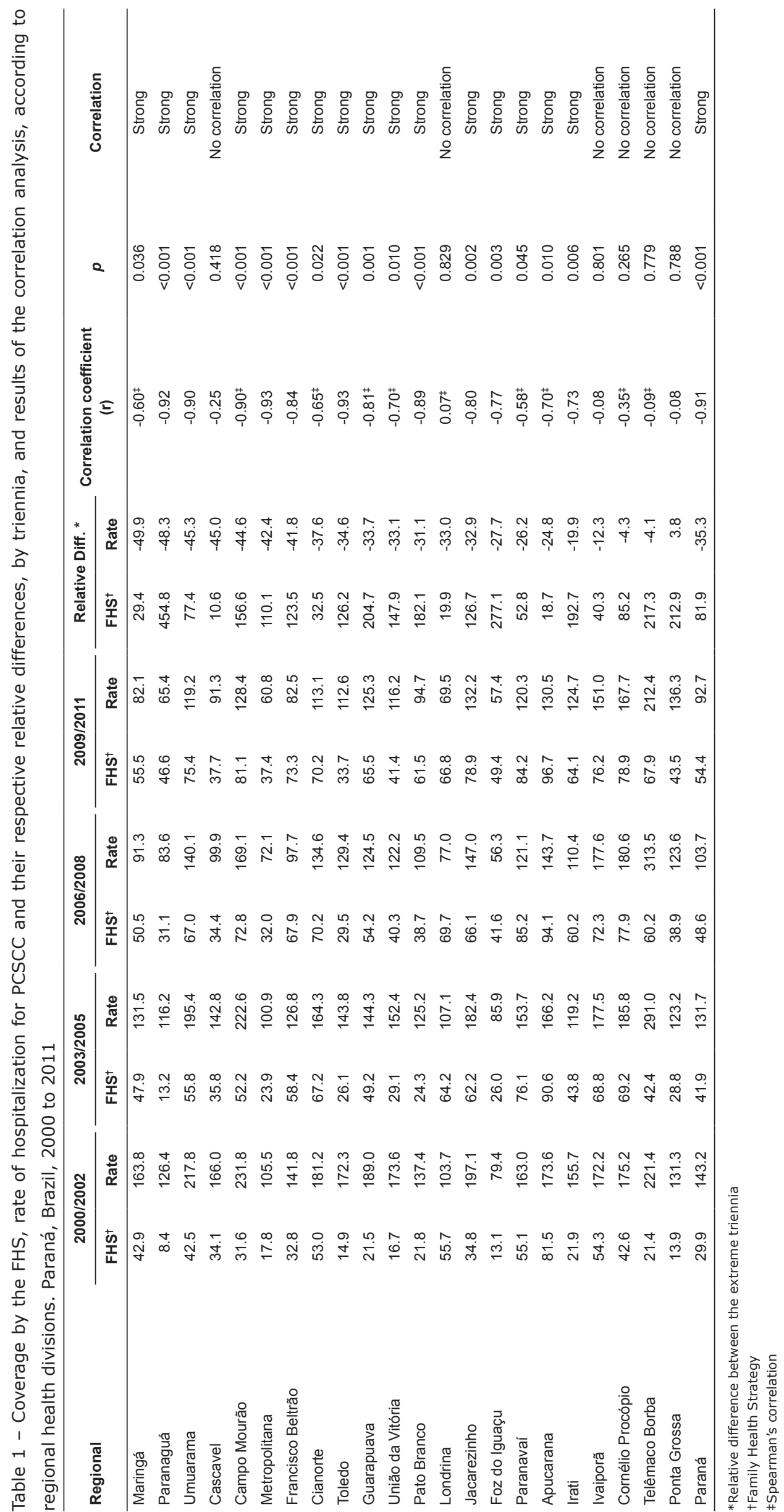




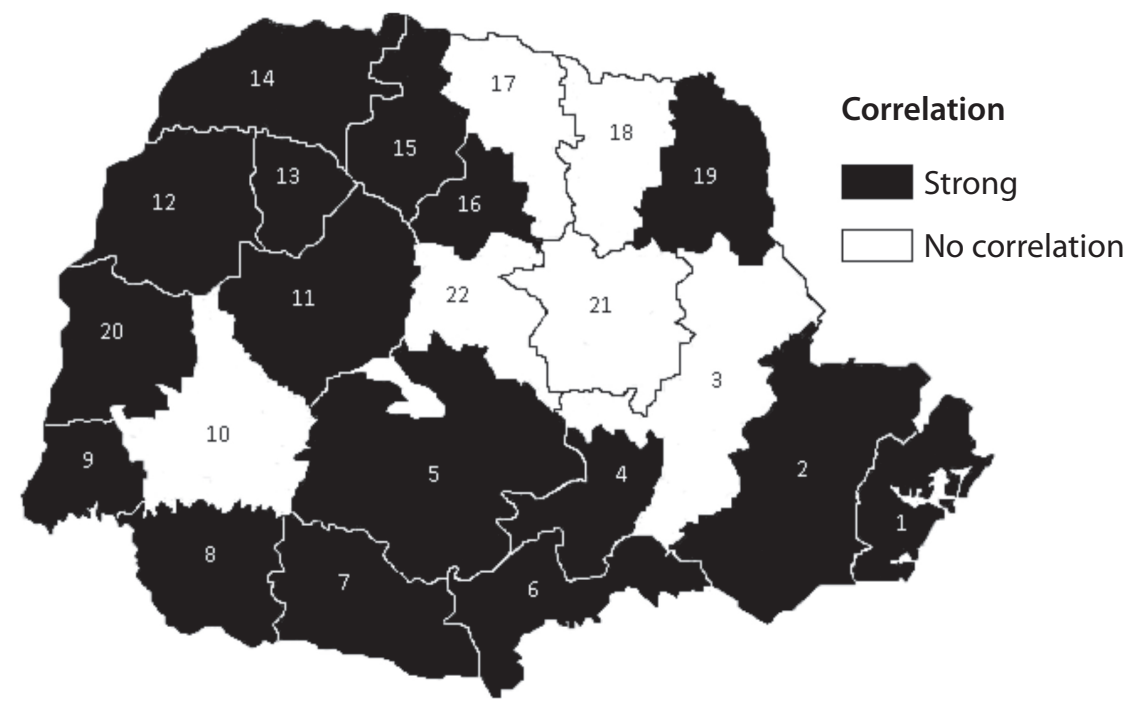

Figure 1 - Map of distribution of the correlation between the rates of hospitalization for PCSCC and the coverage by the FHS, according to regional health divisions. Paraná, Brazil, 2000 a 2011

\section{Discussion}

The expansion of the coverage by the FHS in the State of Paraná proved important during the period studied, reaching, in $2011,96.2 \%$ of municipalities and $55.7 \%$ of the State of Paraná population. Similar behavior was observed in the country in general, with a greater adhesion of small municipalities initially and, secondarily, by the medium and large municipalities, stimulated by the Expansion and Consolidation of Family Health Program (PROESF), which supports by means of specific funding the expansion, qualification and consolidation of the FHS in cities with over 100,000 inhabitants ${ }^{(17)}$. Even though present in most municipalities of the State of Paraná, the FHS still presents difficulties in establishing more accelerated expansion patterns, either by socio-economic reasons of certain regions of the state, or by barriers to access and care practices not committed to change. Although the results are for the State of Paraná, it is possible to assume a similar context for other states of the South of Brazil, because the increase in the coverage by the FHS has been correlated with decrease in mortality caused by circulatory diseases in this region ${ }^{(14)}$.

The expansion of the FHS in Brazil caused the SUS represented one of the largest public systems with universal health access, based on primary care. Due to the large territorial extension, it is essential to observe the local and regional differences, to guarantee an equanimous and quality expansion. The data from this study show that, in the State of Paraná, the expansion and the coverage by the FHS was not homogeneous among the regional health divisions, indicating the existence of different implementation features and organization of the PHC services.

The coverage by the FHS in the regional health divisions presents heterogeneity determined by: high coverages, over the ones provided by the state, and with constantly evolving; percentage similar to the coverage provided by the state; and coverage always low and with certain stability pattern. Therefore, the analysis by regional health division should be considered when comparing the FHS with the rates of hospitalization for sensitive conditions, as indicators of $\mathrm{PHC}^{(12)}$.

By joining to the FHS, municipalities improved their health care service structure, increasing the number of qualified staff and resources, without necessarily changing the healthcare model. Financial incentives are critical for the expansion of the coverage by the FHS, however, they may compromise it, because they are increasingly scarce. On the other hand, proposals as the National Program for Access and Quality Improvement in Primary Care (PMAQ) and the Family Health Support Centers (FHSC) are positive responses, which can help in the problem-solving of the $\mathrm{FHS}^{(7)}$.

The positive impact of the FHS on the hospitalizations for sensitive conditions is observed in the literature about chronic diseases such as CVD. The municipalities with higher population coverage by the FHS have rates of hospitalization for sensitive chronic conditions, $13 \%$ lower than the municipalities with lower coverage, suggesting that the FHS produced improvements to the population health and performance of SUS ${ }^{(4)}$. 
In the present study, the falling in the rates of hospitalization for PCSCC in the state was identified not only in the regional health division of Ponta Grossa. The fall in other regional health divisions showed a heterogeneous behavior in relation to the state, and at the end of the series of hospitalizations, 15 regional health divisions had higher rates in relation to the state. The regional specificities may prevent the implementation of general management standards. However, the Operational Guidelines of the Healthcare Pact (Brazil, 2006) set management commitments focused on the needs of each location. In this scenario, the evaluation and monitoring of the population's health situation provide important insights for managers to deal with dynamic and heterogeneous situations(12), and, in the case of hospital morbidity caused by CVD, become essential for the evaluation of disease behavior and, indirectly, for prevention measures used for its control. Nevertheless, the indicator of hospitalization for PCSC is still not widespread.

The strong and negative correlation between the indicators of the state and of most of the regional health divisions suggests that the increase of the FHS was significant and proportional to the drop in the rates of hospitalization for PCSCC, however, the picture is much more complex. To state that only FHS is responsible for the falls in the hospitalizations may not be consistent because the hospitalizations can also be explained by morbidity, socio-economic and geographic factors, medical practices and health system(18). In the specific case of CVD, it is also considered that the setting of behavioral factors can determine its control or breakthrough because individual choices may be limited by the environment, such as healthy food offer, price and availability of cigarettes and alcohol(19). It cannot fail to consider the socio-economic changes in recent years, including the income improvement, Brazilian society buying power, greater access to education and information, in addition to the characteristic of a long course disease, which requires the active participation of the patient.

Even non-target, the above factors can interfere in the coefficients, however, in this study, the hypothesis follows evidence that regular contact with the primary health service is associated with better adherence to preventive plans of change behavior, a necessary factor for a positive impact in $\mathrm{CVD}^{(20)}$.

To understand the strong and negative correlation among the regional health divisions, it is important to consider some specificities in relation to indicators.
The rates of hospitalization for PCSCC decreased in all regional health divisions, ranging from $-19.9 \%$ to $-49.9 \%$. Regarding the indicator coverage by the FHS, the relative difference showed increase, ranging from $18.7 \%$ to $45.8 \%$. Such difference is due to the high coverages by the FHS at the beginning of the series in some regional health divisions, as in Apucarana, which presented increase of $18.7 \%$, but in 2000 its population coverage was of $81.5 \%$. These differences may indicate different FHS care standards and behavior in this population. Another hypothesis to be highlighted is related to the demographic factor, since the dense urban population in some regional health divisions may greatly influence the results.

Even with no significant linear correlation, it is necessary to analyze some regional indicators, in order to identify, in the results, heterogeneous behaviors that might explain them. Of the six regional health divisions in which there was no correlation, five showed decrease in the hospitalization rates, with the exception of Ponta Grossa. The regional health divisions of Cascavel and Londrina, which are considered macro-regional centers in the state, are populated and developed, and the lack of correlation was determined by stability in the coverage by the FHS during the study period. In regional health division of Cascavel, stability was the result of the low coverage without increasing of its expansion; and in the regional health division of Londrina, stability was determined by a highly representative coverage early on, which remained throughout the period.

The coverage by the private sector, with the expansion of health insurance plans and new hospitals could interfere in the hospitalization rates, reducing hospitalizations by SUS. This is what may have happened in the regional health division of Londrina and Cascavel. However, SUS has better conditions than the supplementary health sector, providing health care systems organized by the FHS, since primary care is not priority in the private sector schedule(7).

Another pattern identified in this group was the situation of the regional health divisions of Cornélio Procópio, Telêmaco Borba and Ivaiporã, which have the highest concentration of small municipalities. The highest hospitalization rates in the regional health divisions with the highest concentration of small municipalities could be result from demand, because even if it can solve the problems at $\mathrm{PHC}$, these regional health divisions tend to decide for hospitalization because they have vacant beds.

It also appears that even with the availability of $\mathrm{SIH}-\mathrm{SUS}$ data, this information system is not capable of 
detecting repeated episodes of hospitalization. A study carried out in the regional health division of Cornélio Procópio revealed individuals hospitalized for $\mathrm{SAH}$ and cerebrovascular diseases in a referral hospital and found a prevalence of $60.4 \%$ of rehospitalizations ${ }^{(21)}$. This data on rehospitalizations can corroborate the high hospitalization rates in the regional health divisions of Telêmaco Borba, Cornélio Procópio and Ivaiporã, which add small municipalities with low complexity hospital network, characteristics that may be artificially feeding the hospitalization rates with rehospitalizations, by the need of hospital maintenance. This situation is considered an example of inefficient allocation of public spending, which could be provided to $\mathrm{PHC}^{(7)}$.

These considerations may be similar when analyzing the behavior identified in the regional health division of Ponta Grossa that, even with increase of its population coverage by the FHS, it was not observed impact on its rates. The problem is challenging, but the health management in each municipality may have important allies in the FHSC - mediators - for the health teams, in the solvability of the actions related to the PCSCC.

It was found that, the data on the coverage by the FHS are updated monthly, however, the information quality is subject to the effectiveness of collection processes, processing, analysis and correct transmission by the Primary Care Information System (SIAB). Failure in supplying the information system and the management of family health teams, with high turnover of professionals, compromises information quality and prevents the full attention. In addition to the information quality, the design adopted could infer in the ecological fallacy, because not always the hospitalized patient was enrolled in the area of coverage by the FHS, and vice versa, including rehospitalizations. Some studies indicate that $75 \%$ of rehospitalizations are preventable, most of them by means of proper management of PHC, constituting the basis of the concept of hospitalizations for PCSC(22).

The availability of hospital beds and HAO paid by SuS decreased in all types of hospitals, mainly in the contracted ones, following the decline in the overall number of hospitalizations ${ }^{(23)}$. In addition, the expansion of ambulatory care, the increase in high complexity ambulatory, distribution of beds and hospitalizations in the specialties, improper to the needs of the population(24), may also be linked to the magnitude of the hospitalization rates, mainly for PCSC.

Based on the considerations and limitations of the study, the use of hospital information and the coverage by the FHS for epidemiological purposes require caution. The questions about the quality of records and data reliability, in addition to contributing to the organization of health information, colaborate to the planning of health team actions ${ }^{(25)}$.

\section{Conclusion}

The implementation, in 2011, of the Strategy and Plan of Action for the Prevention and Control of Noncommunicable Diseases (NCD), aimed to promote the development of health policies. These are focused on services and high impact actions on the determinants of people's health, reaffirming the role and the potential of the FHS monitoring and the treatment and prevention of cardiovascular diseases subject to interventions by $\mathrm{PHC}$. Internationally, $\mathrm{PHC}$ is considered the primary level of management to face these diseases.

Thereby, the results showed that the correlation between population coverage by the FHS and rates of hospitalization for PCSCC in the State of Paraná and in most regional health divisions was strong and negative. The increase in the coverage by the FHS is considered as an important factor for the decline of hospitalization rates. Other studies should be performed in regional health divisions where there was no decline in the rates, in order to better exploit the hospitalizations and probable causes and factors that influence this profile. That's because the impact of the PHC on CVD is not limited to the coverage by the FHS, the access barriers and the improvements in the quality of care offered in these regional health divisions. The influences of other factors may be more dynamic than the actions of the FHS. In this sense, future analysis are necessary to explore socio-economic data for a more in-depth analysis and contextualization of the results.

The study adds knowledge about PCSCC actions, and the results by regional health division revealed as an important analytical tool of the geographic variations and the care needs. In addition, critical nodes were evidenced in the $\mathrm{PHC}$ all over the state, providing insights for monitoring of CVD, as well as the assessment of access and quality of health services to these sensitive conditions.

\section{References}

1. World Health Organization. Global status report on non communicable diseases 2010. Geneva: World Health Organization; 2011. 
2. Freund T, Peters-Klimm F, Rochon J, Mahler C, Gens ichen J, Erler A, et al. Primary care practice-based care management for chronically ill patients (PraCMan): study protocol for a cluster randomized controlled trial [ISRCTN56104508]. Trials. 2011; 12(163). DOI: $10.1186 / 1745-6215-12-163$.

3. Ministério da Saúde (BR). Departamento de Informática do SUS - DATASUS. Mortalidade hospitalar do SUS por local de internação - Brasil. [Internet]. [acesso 22 fev 2014]. Disponível em: http://tabnet. datasus.gov.br/cgi/tabcgi.exe?sih/cnv/niuf.def.

4. Macinko J, Dourado I, Aquino R, Bonolo PF, LimaCosta MF, Medina MG, et al. Major Expansion Of Primary Care In Brazil Linked To Decline In Unnecessary Hospitalization. Health Aff. 2010;29(12):2149-60. DOI: 10.1377/hlthaff.2010.0251.

5. Nedel FB, Facchini LA, Martín M, Navarro A. Características da atenção básica associadas ao risco de internar por condições sensíveis à atenção primária: revisão sistemática da literatura. Epidemiol Serv Saúde. 2010;19(1):65-75.

6. Mathias TAF, Mello Jorge MHP. Hospitalização e mortalidade em idosos: um exercício de análise comparativa. Ciênc Cuid Saúde. jan-abr 2005;4(1):25-36. 7. Mendes EV. O cuidado das condições crônicas na atenção primária à saúde: o imperativo da consolidação da estratégia da saúde da família. Brasília: Organização Pan-Americana da Saúde; 2012.

8. Fernandes VBL, Caldeira AP, Faria AA, Neto JFR. Hospitalizations sensitive to primary care as an evaluation indicator for the Family Health Strategy. Rev Saúde Pública. 2009; 43(6):928-36.

9. Mendes EV. As redes de atenção à saúde. Brasília: Organização Pan-Americana da Saúde; 2011.

10. Ministério da Saúde (BR). Portaria no 221, de 17 de abril de 2008. Publica a lista brasileira de internações por condições sensíveis à atenção primária. Diário Oficial da União, Brasília, p. 70-71. 18 abr. Seção 1.

11. Mendis S, Al Baschir I, Dissanayabe L, Varghese C, Fadhil I, Marhe E, et al. Gaps in Capacity in Primary Care in Low-Resource Settings for Implementation of Essential Noncommunicable Disease Interventions. Int J Hypertens. 2012:584041. DOI: 10.1155/2012/584041.

12. Campos $A Z$, Theme-Filha MM. Internações por condições sensíveis à atenção primária em Campo Grande, Mato Grosso do Sul, Brasil, 2000 a 2009. Cad Saúde Pública. 2012;28(5): 845-55.

13. Barreto JOM, Nery IS, Costa MSC. Estratégia Saúde da Família e internações hospitalares em menores de 5 anos no Piauí, Brasil. Cad. Saúde Pública. 2012; 28(3): 515-526.

14. Ceccon RF, Borges DO, Paes LG, Klafke JZ, Viecilli PR. Mortalidade por doenças circulatórias e evolução da saúde da família no Brasil: um estudo ecológico. Ciênc Saúde Coletiva. 2013;18(5):1411-6.

15. Aquino EML, Barreto SM, Benseñor IM, Carvalho MS, Chor D, Duncan BB, et al. Brazilian Longitudinal Study of Adult Health (ELSA-Brasil): objectives and design. Am J Epidemiol. 2012;175(4)1:315-24. DOI: 10.1093/AJE/ KWR294.

16. Hulley SB, Cummings SR, Browner WS, Grady D, Hearst N, Newman TB. Delineando a pesquisa clínica: uma abordagem epidemiológica. 3.ed. Porto Alegre: Editora Artmed; 2008.

17. Conill EM. Ensaio histórico-conceitual sobre a Atenção Primária à Saúde: desafios para a organização de serviços básicos e da Estratégia Saúde da Família e centros urbanos no Brasil. Cad Saúde Pública. 2008;24(Supl 1):S7-S27.

18. Deraas TS, Berntsen GR, Hasvold T, Forde OH. Does long-term care use within primary health care reduce hospital use among older people in Norway? A national five-year population-based observational study. BMC Health Serv Res. 2011;11:28. DOI: 10.1186/14726963-11-287.

19. Macinko J, Dourado I, Guanais FC. Doenças Crônicas, Atenção Primária e Desempenho dos Sistemas de Saúde: Diagnósticos, instrumentos e intervenções. Banco Interamericano de Desenvolvimento; nov 2011. $36 \mathrm{p}$.

20. Coleman K, Austin BT, Brach C, Wagner EH. Evidence On The Chronic Care Model In The New Millennium. Health Aff. 2009;28(1):75-85.

21. Carvalho EB. Caracterização das pessoas internadas por hipertensão arterial e doenças cerebrovasculares em um hospital de referência regional: perfil de risco e utilização de serviços ambulatoriais [Dissertação de Mestrado]. Londrina (PR): Universidade Estadual de Londrina; 2010.

22. Caminal J, Starfield B, Sánchez E, Casanova C, Morales $M$. The role of primary care in preventing ambulatory care sensitive conditions. European J Public Health. 2004; 14:246-51.

23. Ribeiro JM. O desenvolvimento do suS e racionamento de serviços hospitalares. Ciênc Saúde Coletiva. 2009;14(3):771-82.

24. Mendes ACG, Sá DA, Miranda AMD, Lyra TM, Tavares RAW. Assistência pública de saúde no contexto da 
transição demográfica brasileira: exigências atuais e futuras. Cad Saúde Pública. 2012;28(5):955-64.

25. Arruda GO, Molena-Fernandes CA, Mathias TAF, Marcon SS. Hospital morbidity in a médium-sized city: differentials between men and women. Rev. Latino-Am. Enfermagem. 2014;22(1):19-27. 